\title{
Workforce scheduling: A new model incorporating human factors
}

\author{
Mohammed Othman, Gerard J. Gouw, Nadia Bhuiyan \\ Concordia University (Canada) \\ mobothman2002@yahoo.com,goum@alcor.concordia.ca, bhuiyan@,alcor.concordia.ca
}

Received: January 2012

Accepted: September 2012

\section{Abstract:}

Purpose: The majority of a company's improvement comes when the right workers with the right skills, behaviors and capacities are deployed appropriately throughout a company. This paper considers a workforce scheduling model including human aspects such as skills, training, workers' personalities, workers' breaks and workers' fatigue and recovery levels. This model helps to minimize the hiring, firing, training and overtime costs, minimize the number of fired workers with high performance, minimize the break time and minimize the average worker's fatigue level.

Design/methodology/approach: To achieve this objective, a multi objective mixed integer programming model is developed to determine the amount of hiring, firing, training and overtime for each worker type.

Findings: The results indicate that the worker differences should be considered in workforce scheduling to generate realistic plans with minimum costs. This paper also investigates the effects of human fatigue and recovery on the performance of the production systems.

Research limitations/implications: In this research, there are some assumptions that might affect the accuracy of the model such as the assumption of certainty of the demand in each period, and the linearity function of Fatigue accumulation and recovery curves. These assumptions can be relaxed in future work.

Originality/value: In this research, a new model for integrating workers' differences with workforce scheduling is proposed. To the authors' knowledge, it is the first time to study the effects of different important human factors such as human personality, skills and fatigue and recovery in the workforce scheduling process. This research shows that considering both 
technical and human factors together can reduce the costs in manufacturing systems and ensure the safety of the workers.

Keywords: fatigue; human factors; personality; workforce scheduling

\section{Introduction}

Effective workforce scheduling is one of the most critical tasks affecting performance of manufacturing systems. It is important to assign the right job to the right person at the correct time. Also, it is very important to have a close match between workers' skills, attitudes and strength and his/her tasks he/she performs (for simplicity, we will use he/him hereafter). This needs an effective workforce scheduling system. This system aims to reduce waste in employing people, lessen uncertainty about current personnel levels and future needs, and avoid worker and skills shortages or surpluses by hiring the right workers in appropriate numbers. Traditional workforce scheduling tools are limited and cumbersome. They are concerned with 'head count' rather than 'head content', which prevents the resulting schedule from being flexible enough to follow the growing demand of fast changing business dynamics (Birch, O'Brien-Pallas, Alksnis, Tomblin Murphy \& Thomson, 2003; Castley, 1996; Jensen, 2002). A major problem with existing models is the absence of the most important human factors inherent in the production system. As one of the main elements in a production system, human issues cannot be ignored without significantly reducing the benefits of the production system. Considering human factors in production planning has the potential to improve both injury risk and production performance (Neumann \& Medbo, 2009; Udo \& Ebiefung, 1999). It is important to integrate human factors early in the production planning phase because early changes to the product and work are less costly and easier to make than are late changes. Workforce planning is a systematic identification and analysis of what a company is going to need in terms of the size, type, and quality of workforce to achieve its strategic objectives. It determines the right number of the right people in the right place at the right time. In this paper, a new model for workforce scheduling to support production planning is developed to achieve better production performance while reducing risks to operator health. The paper is organized as follows: Section 2 presents a literature review of human factors and their relation to the planning process. Section 3 describes the workforce scheduling model formulation and the notation used. Next, Section 4 presents the results and insights generated from the proposed model. Finally, conclusions and suggestions for future research directions are summarized in Section 5.

\section{Literature review}

Human Factors (HF), or ergonomics, has been defined as "the theoretical and fundamental understanding of human behavior and performance in purposeful interacting socio-technical 
systems, and the application of that understanding to the design of interactions in the context of real settings" (Wilson, 2000). During the last decades, ergonomics have been considered minimally in building production systems. Most business managers have accepted the idea that ergonomics are working as protectors of workers, rather than creators of systems (Dul \& Neumann, 2009; Perrow, 1983). They generally associate ergonomics with health and safety issues rather than with the effectiveness of organizations (Jenkins \& Rickards, 2001). Ergonomics is considered too late in the production system development process, making most managerial decisions hard to change (Helander 1999; Jensen, 2002; Neumann \& Medbo, 2009). Perrow (1983) mentioned that the main problem is that human factors specialists have limited influence and control within the organizational context. Also, they have no control of strategic resources and a weak network in and outside of the organization. However, it is shown that ergonomics can contribute to different company strategies and support the objectives of different business functions in the organization (Dul \& Neumann, 2009). On the other hand, many ergonomics models have been developed without a clear understanding of how they could be implemented in a specific company (Butler, 2003; Hagg, 2003). Berglund and Karltun (2007) studied the effects of the human, technology and organizational aspects on the outcome of the production scheduling processes. Based on their study, schedulers need to consider uncertainty, their experience, problem solving, workers' differences, technical system limitations, the degree of proximity between employees and their informal authority. Jensen (2002) presents approaches and tools developed in Scandinavian countries. He explained that the changes in the ergonomics role inside a company require understanding the organizational prerequisites. He proposed a political agent in order to complement the roles of an expert and a facilitator. He also suggested developing studies on the management of ergonomics and organizational development.

There are many reasons for not considering human issues early into production planning. Helander (1999) discussed seven common reasons for not considering ergonomics early in the production system development process. Some of the common misconceptions regarding ergonomics are that many people think that it is for the design of chairs and that it is just common sense; the research in ergonomics is too abstract to be useful; people are adaptive, so there is no need for ergonomics; and the technical system should be designed first before considering ergonomics. Bidanda, Ariyawonggrat, Needy, Norman, and Tharmmaphornphilas (2005) mentioned that the major reason is that human issues are typically difficult to quantify. However, none of these are reasons to not consider human factors early in the production process.

In reality, there is a tremendous variability in individual capabilities. The result is that most production system designs ignore the effects of the human differences in production system design. Buzacott (2002) indicates that individual differences can result in substantial loss in throughput. Worker differences are a fundamental element to consider when assigning workers 
to a workstation on the assembly floor. On the other hand, Broberg (2007) has pointed out that human factors tools to integrate ergonomics into the design process are not known by engineers. Some tools for handling human factors in planning are creating digital human models, integrating ergonomics into predetermined motion time systems and integrating ergonomics into discrete event simulation (DES). However, DES has been considered to be an appropriate tool that can incorporate human aspects at the earliest planning stage for optimal performance (Neumann \& Medbo, 2009). Some ideas on how to integrate human performance modeling with DES in assembly lines are suggested (Siebers, 2004; 2006). Due to the variation in human performance, there is a need for non-deterministic models of worker performance. Dul and Neumann (2009) provided a conceptual framework to help ergonomists in research, education and practice to understand how to support the strategic objectives of a company. This framework helps ergonomics experts to focus on ergonomics from the point of view of business performance rather than occupational health and safety.

There have been many interesting developments on the technical side of planning and scheduling processes. Many researchers considered a few human aspects in their quantitative models. Da Silva, Figueira, Lisboa, and Barman (2006) developed an aggregate production planning model that includes workers' training, legal restrictions on workload and workforce size. Jamalnia and Soukhakian (2009) have developed a fuzzy multi-objective nonlinear programming model for aggregate production planning problem in a fuzzy environment. Learning curve effects have been considered in formulating the model. Wirojanagud, Gel, Fowler, and Cardy (2007) used the general cognitive ability metric to model individual difference in efficacy of cross-training and worker productivity. Azizi, Zolfaghari and Liang (2010) considered workers motivation, learning and forgetting factors and workers' skills to measure employees' boredom and skill variations during a production horizon. Corominas, Olivella and Pastor (2010) have taken into account learning curves and workers experience in modeling a scheduling problem. Also, researchers utilized mathematical models, heuristics and simulation to study the impact of cross-training on system performance. Stewart, Webster, Ahmad and Matson (1994) developed four optimization models for different cross-training scenarios to assist managers in deciding optimum tactical plans for training and assigning a workforce according to the skills required by a forecasted production schedule. Felan and Fry (2001) investigated the concept of a multi-level flexibility workforce using simulation. The results indicate that it is better to have a combination of workers with high flexibility and workers with no flexibility rather than employing all workers with equal flexibility. Blumberg and Pringle (1982) developed a model that can link between worker motivation and productive performance. In their paper, they suggested that expected work performance of individuals is determined by three factors: Capacity, Opportunity and Willingness. Jaber and Neumann (2010) developed a mixed-integer linear programming (MILP) model that describes fatigue and recovery in dual-resource constrained systems. The results obtained from their model suggest that short rest breaks after each task, short cycle times and faster recovery rates improve the 
system's performance. Fatigue may be defined as a physical and mental weariness existing in a person and harmfully affecting the ability to perform work. Worker fatigue can greatly impact system performance in terms of quality (Eklund, 1997). It can significantly affect human productivity (Oxenburgh, Marlow, \& Oxenburgh, 2004). Inordinately long working hours and poorly planned shift work can result in employee fatigue.

As discussed above, the literature review demonstrated that most of the work on workforce planning and scheduling assumed that workers are identical. The problem seems to be systemic and there is an obvious need to integrate ergonomics processes into the organization early so that underlying principles can be incorporated. Our research will contribute to the literature by extending existing models of service workforce planning and scheduling beyond current capabilities. This model will incorporate human issues such as skills, training, worker personalities, worker recovery and worker fatigue. Four objective functions are considered in the proposed model. The first one is cost minimization and the second one is top performance workforce firing minimization, the third one is idle time minimization and the last one is fatigue rate minimization. In summary, ergonomics must be implemented concurrently with production planning in order to improve planning process performance. The problem description, assumptions and formulation are given in the next section.

\section{Mathematical modelling of the multiple-objective workforce scheduling problem}

In this paper, we analyze the scheduling problem in a job shop environment consisting of different machines types, which are grouped into several machine levels depending on many factors such as the complexity and sophistication of the machine, the quantity of the process plans available and training budget. For example, if we have three machine levels, machine level one is the less complicated one and machine level three is the most complicated level. Worker flexibility can be achieved by using overtime and training. Workers are grouped according to different human skills and personalities and we have made the assumption that the number of worker skill levels is equal to the number of machine levels. Personality can be defined as a dynamic and organized set of characteristics possessed by a person that uniquely influences his or her cognitions, motivations, and behaviors in various situations. We assume that each worker will have at least one personality level that can be assigned to a certain machine level depending on his personal traits such as constructive, creative, dynamic, educated, efficient, etc. They are grouped within the categories of an individual's miscellaneous attributes and skills. We divided the skill levels and the personality levels into three levels: level 1 indicates the lowest level, level 2 indicates the middle level, and level 3 indicates the highest level. In contemporary psychology, the dimensions of personality which are used to describe human personality are openness, conscientiousness, extraversion, agreeableness, and neuroticism. Openness includes characteristics such as curiosity, novelty, imagination, insight and variety. Conscientiousness is a tendency to show self-discipline and being organized, and 
achievement-oriented. Extraversion includes characteristics such as sociability, excitability, assertiveness, and talkativeness. Agreeableness includes characteristics such as morality, trust, cooperation, kind and sympathy. Finally, Neuroticism is the tendency to experience emotional instability, anger, anxiety, sadness and depression. In this paper, these traits are measured based on percentile scores. Level 1 indicates the range from 0 to 33.3th percentile, level 2 indicates the range from 33.4 to 66.6 percentile, and level 3 indicates the range from 66.7 to $100^{\text {th }}$ percentile. For example, people with high scores on conscientiousness tend to be responsible, organized and mindful of details, whereas people with low scores on openness tend to have less curiosity and more traditional interests. However, people with similar characteristics are grouped into personality levels, which reduce the variability of considering individual personality profiles. Special questionnaires can be developed and validated for use in applied research settings to measure the Big Five domains. If, for example, a worker wants to improve his skills, training can be used. It can also help the person to grow and develop his personality traits. Layoffs or hiring new workers affect the performance of the present workers because they need to be trained to the same level as the previous fired workers. Workers have a certain capacity during work, which is the maximum endurance time, defined as the length of time that workers can continue to work without becoming fatigued. It is assumed that endurance time increases as the personality level is increased. When the productive time increases, the average workload on the worker increases, so that rest breaks have to be given for the physiological recovery of a worker. Relaxation allowance is used to assist recovery from fatigue. It is an addition to the basic time intended to provide the worker with the opportunity to recover from the physiological and psychological effects of carrying out specified work under specified conditions. The amount of allowance will depend on the nature of the job, personality attributes and environment. The proposed mathematical programming model is based on the following assumptions:

- All the objective functions and constraints are linear equations.

- The demand in each period is deterministic over time.

- Fatigue accumulation and recovery curves are linear over time.

- The fraction of maximum load capability is applied continuously by the worker when performing a task for a period equivalent to the task's duration.

- The length of the break between tasks is not long enough to result in full recovery.

- The top performers have skill and personal levels greater than or equal to 2 .

- The length of the shift work of a worker is less than 12 hours including overtime.

The model presented herein is deterministic and in order to satisfy the total demand of each period, we are interested in determining:

- How many workers to assign to each machine level in each period?

- How many workers, with which skill levels, to hire or fire in each period? 
- How many workers to train from lower skill level to higher one in each period?

- How many hours a worker with specific skill and personality level can work on overtime basis?

- How long a worker spends on a task in each period?

- How long a break time following any task a worker can take?

\subsection{Model characteristics}

The model developed is a multi-objective integer programming model that allows a number of different staffing decisions to be made (e.g. hire, train, fire and overtime) in order to minimize the sum of hiring, firing, training and overtime costs and minimize the top performance workers fired over all periods, minimize idle (unproductive) time and minimize the physical load on the workforce.

\subsection{Notation and model variables}

In presenting the model, the following notations are used:

\section{Indices:}

$\begin{aligned} t & =\quad \text { Index of planning periods (days) }, t=1,2, \ldots, T \\ j, k & =\quad \text { Indices of human skill levels, } j, k=1,2, \ldots, S \\ x, y & =\quad \text { Indices of machine levels, } x, y=1,2, \ldots, M L \\ p & =\quad \text { Index of personality attributes, } p=1,2, \ldots, P \\ s & =\quad \text { Index of tasks, } s=1,2, \ldots, T S\end{aligned}$

\section{Parameters:}

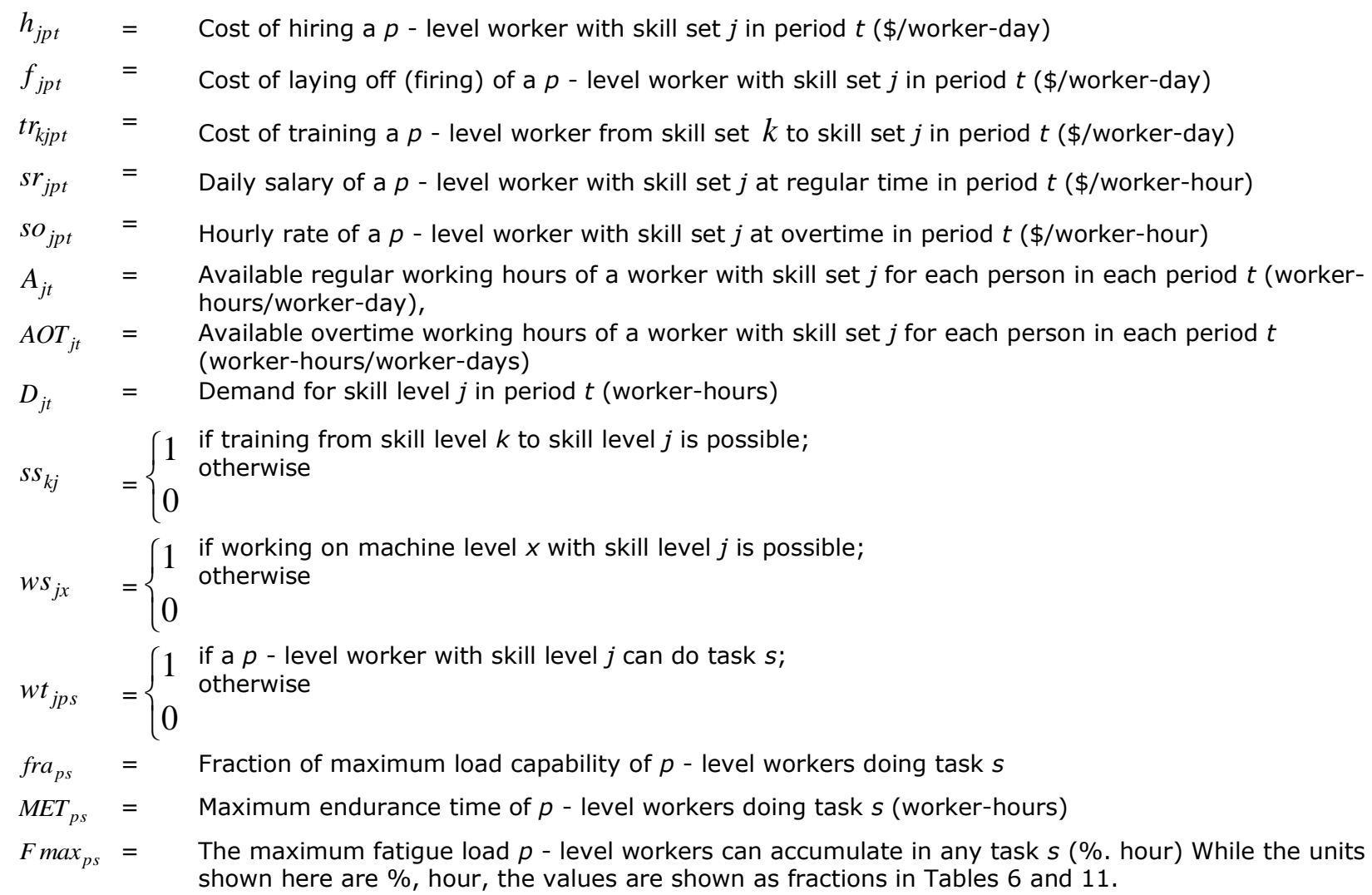




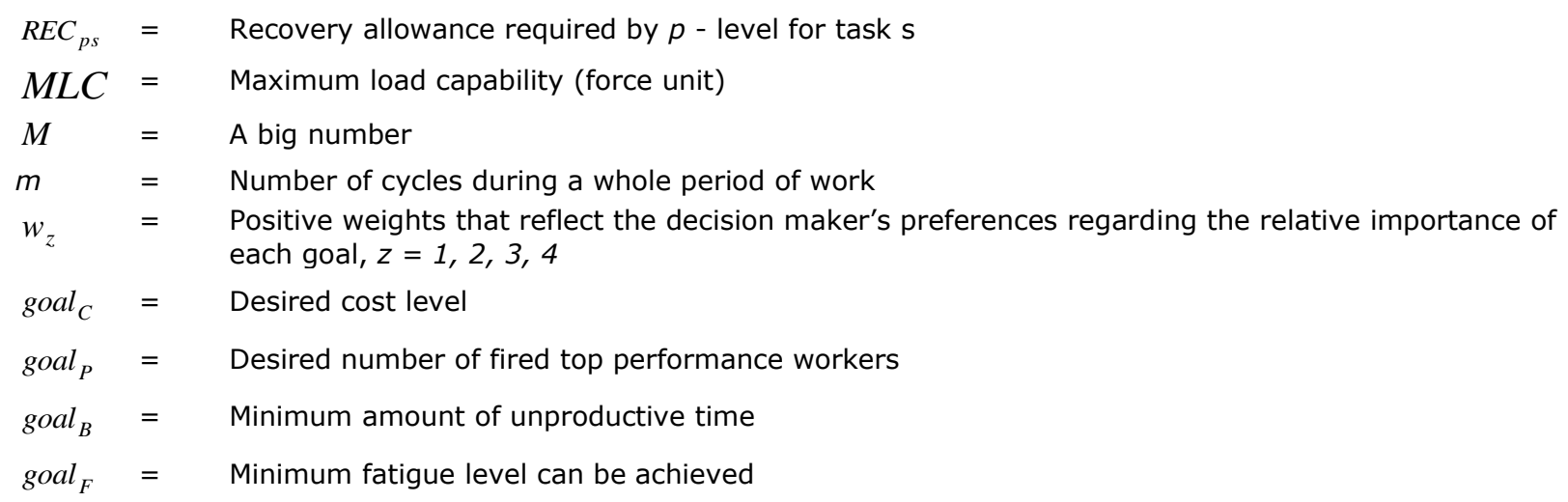

Decision variables:

$W_{j p t x}=$ Number of $p$ - level workers with skill set $j$ required to be assigned to machine level $x$ in period $t$

jptx (worker-days)

$H_{j p t x}=$ Number of $p$ - level workers with skill set $j$ hired and assigned to machine level $x$ in period $t$ (worker-

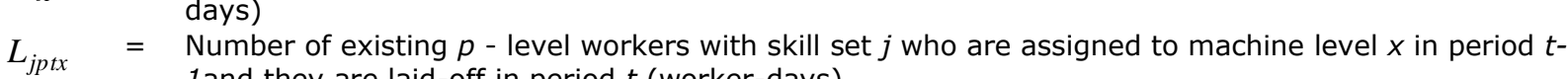

1 and they are laid-off in period $t$ (worker-days)

$Y_{\text {kjptyx }}=$ Number of $p$ - level workers who were assigned to machine level $y$ and then are trained from skill set $k$

to skill set $j$ and assigned to a higher machine level $x$ in period $t$ (worker-days)

$O T_{j p t x}=$ Overtime hours of $p$ - level workers with skill set $j$ in period $t$ (worker-hours)

$T I_{j p t s x}=$ Time $p$ - level workers with skill set $j$ spend on task $s$ on machine level $x$ during period $t$ (workerhours)

$B_{j p t s x}=$ Break time of $p$ - level workers with skill set $j$ following task $s$ on machine level $x$ during period $t$

(worker-hours)

$d_{C}^{+}, d_{C}^{-}=$The positive and negative deviation from goal $C$

$d_{P}^{+}, d_{P}^{-}=$The positive and negative deviation from goal $_{P}$

$d_{B}^{+}, d_{B}^{-}=$The positive and negative deviation from goal $_{B}$,

$d_{F}^{+}, d_{F}^{-}=$The positive and negative deviation from goal $_{F}$.

\section{Objective function:}

The mathematical programming model of the workforce scheduling problem is now given as follows:

Minimize: $O B J=w_{1} \times d_{C}^{+}+w_{2} \times d_{P}^{+}+w_{3} \times d_{B}^{+}+w_{4} \times d_{F}^{+}$

\section{Subject to:}

\section{Goal constraints:}

$$
\begin{aligned}
& \sum_{t=1}^{T} \sum_{p=1}^{P} \sum_{j=1 x=1}^{S} \sum_{x=1}^{M L}\left(h_{j p t} \times H_{j p g t}+f_{j p t} \times L_{j p t x}+s r_{j p t} \times W_{j p t x}+s o_{j p t} \times O T_{j p t x}\right)+\sum_{t=1}^{T} \sum_{p=1}^{P} \sum_{j=1 k=1 x=1}^{S} \sum_{x=1}^{S} \sum_{y=1}^{M L M L}\left(t r_{j p k t} \times Y_{j p k t x y}\right)+d_{C}^{-}-d_{C}^{+}=g o a l_{C} \\
& \sum_{t=1}^{T} \sum_{p=2}^{P} \sum_{j=2}^{S} \sum_{x=1}^{M L} L_{j p t x}+d_{P}^{-}-d_{P}^{+}=\text {goal }_{P} \\
& \sum_{t=1}^{T} \sum_{p=1}^{P} \sum_{j=1}^{S} \sum_{s=1}^{T S} \sum_{x=1}^{M L}\left(B_{j p t s x}\right)+d_{B}^{-}-d_{B}^{+}=\text {goal }_{B}
\end{aligned}
$$

$$
\frac{m \times \sum_{t=1}^{T} \sum_{p=1}^{P} \sum_{j=1 s=1}^{S} \sum_{x=1}^{T S} \sum_{x=1}^{M L}\left(f r a_{p s} \times T I_{j p t s x}\right)-m \times \sum_{t=1}^{T} \sum_{p=1}^{P} \sum_{j=1 s=1}^{S} \sum_{s=1}^{8} \sum_{x=1}^{M L}\left(\frac{f r a_{p s}}{R E C_{p s}} \times B_{j p t s x}\right)-(m-1) \times \sum_{t=1}^{T} \sum_{p=1}^{P} \sum_{j=1 s=9}^{S} \sum_{s=1}^{9} \sum_{x=1}^{M L}\left(\frac{f r a_{p s}}{R E C_{p s}} \times B_{j p t s x}\right)}{2 \times F \max x_{p s}}+d_{F}^{-}-d_{F}^{+}=g_{\text {oal }}
$$




\section{Other constraints:}

$$
\begin{aligned}
& \sum_{p=1 x=1}^{P} \sum_{x=1}^{M L}\left(A_{j t} \times W_{j p t x}\right)-N \times \sum_{s=1}^{T S}\left(B_{j p t s x}\right)+\sum_{p=1 x=1}^{P} \sum_{j p}^{M L} O T_{j p t x}=D_{j t} \quad \forall j, t \\
& N \times \sum_{s=1}^{T S}\left(T I_{j p t s x}+B_{j p t s x}\right)-N \times B_{j p t 9 x}=A_{j t} \times W_{j p t x} \quad \forall j, p, t, x \\
& m \times \sum_{s=1}^{T S}\left(f r a_{p s} \times T I_{j p t s x}\right)-m \times \sum_{s=1}^{8}\left(\frac{f r a_{p s}}{R E C_{p s}} \times B_{j p t s x}\right)-(m-1) \times \frac{f r a_{p 9}}{R E C_{p 9}} \times B_{j p t 9 x} \leq F \max _{p s} \quad \forall j, p, t, x \\
& W_{j p t x}=W_{j p t-1 x}+H_{j p t x}-L_{j p t x}+\sum_{\substack{k=j-1 \\
j \geq 2}}^{j} \sum_{\substack{y=x-1 \\
x \geq 2}}^{x}\left(Y_{k j p t y x}\right)-\sum_{\substack{k=j+1 \\
k \geq 2}}^{k} \sum_{\substack{y=x+1 \\
y \geq 2}}^{y}\left(Y_{j k p t x y}\right) \quad \forall j, p, t, x \\
& O T_{j p t x} \leq A O T_{j t} \times W_{j p t x} \\
& \forall j, p, t, x \\
& \sum_{\substack{k=1 \\
k>j}}^{S} \sum_{y=1}^{M L} Y_{j k p t x y}+L_{j p t x} \leq W_{j p, t-1, x} \\
& L_{j p t x} \leq M \times w s_{j p x} \\
& \forall j, p, t, x \\
& \forall j, p, t, x \\
& H_{j p t x} \leq M \times w s_{j p x} \\
& \forall j, p, t, x \\
& Y_{k j p t y x} \leq M \times w s_{k p y} \\
& \forall j, k, p, t, x, y \\
& Y_{k j p t y x} \leq M \times w s_{j p x} \\
& \forall j, k, p, t, x, y \\
& Y_{k j p t y x} \leq M \times s s_{k j} \\
& \forall j, k, p, t, x, y \\
& \sum_{k=1}^{S} Y_{k j p t y x} \leq M \times Z_{j p t x} \\
& \forall j, p, t, x, y \\
& L_{j p t x} \leq M\left(1-Z_{j p t x}\right) \\
& \forall j, p, t, x \\
& H_{j p t x} \leq M \times U_{j p t x} \\
& \forall j, p, t, x \\
& L_{j p t x} \leq M\left(1-U_{j p t x}\right) \\
& \forall j, p, t, x \\
& T I_{j p t s x} \leq m \times M E T_{p s} \times W_{j p t x} \\
& \forall j, p, t, s, x \\
& T I_{j p t s x} \leq M \times W T_{j p s} \\
& \forall j, p, t, s, x \\
& B_{j p t s x} \leq R E C_{p s} \times T I_{j p t s x} \\
& \forall j, p, t, s, x \\
& M E T_{p s}=\alpha \times e^{-\beta \times f r a p s} \quad \forall p, s \\
& F_{\text {max }}=M L C \times f r a_{p s} \times M E T_{p s} \quad \forall p, s \\
& W_{j p t x}, H_{j p t x}, L_{j p t x}, Y_{k j p t y x}, O T_{j p t x}, T I_{j p t s x}, B_{j p t s x}, d_{c}^{-}, d_{c}^{+}, d_{p}^{-}, d_{p}^{+}, d_{t}^{-}, d_{t}^{+}, d_{f}^{-}, d_{f}^{+}, \geq 0 \quad \forall j, k, p, t, x, y \\
& Z_{j p t x}, U_{j p t x} \in\{0,1\} \\
& \forall j, p, t, x
\end{aligned}
$$


The objective function aims to minimize: all costs incurred including worker hiring and firing, training costs and overtime costs; the top performer layoffs; idle (unproductive) time; and the weighted average fatigue rate. The purpose of optimization is to minimize the deviations from specific goals based on the importance of each one. Constraints (1), (2), (3) and (4) represent the cost goal, top performance goal, unproductive time goal and fatigue level goal constraints, respectively. Constraint (5) shows that the total regular time a worker spends on a task plus the total overtime hours are equal to the number of hours required for each skill in each period. Constraint (6) shows that the total regular time a worker spends on a task plus the total breaks and interruptions during should not be greater than the available labour capacity. Constraint (7) ensures that the fatigue rate at the end of a period has to be less than the maximum fatigue load a worker can accumulate in any task. Constraint (8) ensures that the workforce in any period should equal the workforce in the previous period plus the new hires and is trained to the upper level minus the layoffs. Constraint (9) ensures the overtime workforce available should be less than the maximum overtime workforce available in each period. Constraint (10) ensures that the total number of workers who are assigned to machine level $x$ in period $t-1$ and now fired or trained for upper skill levels should not be greater than the number of workers required in the previous period. Constraint (11) ensures that workers can be fired if and only if the assignment is possible. Constraint (12) denotes that workers can be hired if and only if the assignment is possible. Constraint (13) ensures that training for better skills is possible if and only if the previous assignment is possible. Constraint (14) ensures that training for better skills is possible if and only if the latter assignment is possible. Constraint (15) ensures that training for better skills is possible if and only if training to that skill is possible. Constraints (16) and (17) guarantee the workers who are trained for skill level $j$ should not be fired in the same period. Constraints (18) and (19) ensure that either hiring or firing workers occurs but not both. Constraint (20) ensures that the processing time for any task cannot exceed the maximum endurance time for any individual performing that task. Constraint (21) states that the worker can perform any task if and only if the worker assignment to that task is possible. Constraint (22) ensures that the break time following any task is to be less than or equal to the recommended recovery duration for that task. Constraint (23) calculates the value of maximum endurance time based on the fraction of the maximum load capability applied when performing certain task. Constraint (24) calculates the total limit for maximum fatigue index. Finally, constraints (25) and (26) are the non-negativity constraints.

Goal programming can be used to solve the multi-objective functions. It provides a way of striving towards conflicting objectives simultaneously. The basic approach of goal programming is to establish a specific target for each of the objectives, formulate an objective function for each objective, and then seek a solution that minimizes the (weighted) sum of deviations of these objective functions from their targets. There are two methods for solving goal programs: the non-preemptive method (weights method) and the preemptive method. The weights 
methods form a single objective function consisting of the weighted sum of the goals, where all goals are roughly comparable of importance. On the other hand, the preemptive method organizes the goals one at a time starting with the highest priority goal and terminating with the lowest one without degrading the quality of a higher-priority goal (Hillier \& Lieberman, 2010). In this paper, the non-preemptive method is used to solve the problem. The decision maker must determine penalty weights that reflect his preferences regarding the relative importance of each goal. For example, penalty weights equal to 1 signify that all goals carry equal weights. The determination of the specific values of these weights is subjective. Different methods have been developed to estimate the weight values (Tamiz, Jones, \& Romero, 1998; Cohon, 1978). The solution procedure considers one goal at a time, starting with the costs minimization goal, and terminating with the fatigue minimization goal. The process is carried out such that the solution obtained from a first goal never degrades the other goals solutions. However, weighted goal programming considers all goals simultaneously within a composite objective function comprising the sum of all deviational variables of the goals from their targets. One of the drawbacks of this method is the use of different units of deviational variables in an objective function where the sums of unwanted deviational variables are minimized. This different measurement unit may damage the relative importance of the objective to the decision maker or cause an unintentional bias towards the objectives with a larger magnitude (Tamiz et al., 1998). This problem can be solved by the use of a normalization procedure or simply using same unit for all deviational variables in the objective function. Different normalization techniques are suggested (De Kluyver, 1979; Jones, 1995; Masud \& Hwang, 1981; Wildhelm, 1981). In this research, the following steps are used to handle multi-objective functions:

- Define LP1 as the first Linear programming model with objective function: minimize goal $c$; LP2 is the second linear programming model with objective function: minimize goal $P$; LP3 is the third linear programming model with objective function: minimize goal ${ }$; LP4 is the fourth linear programming model with objective function: minimize goal $F$.

- Identify the goal values of each model in step 1 , and add these values to the right hand side of each constraint (1), (2), (3) and (4), respectively, to ensure the goals are satisfied.

- Add penalty weights to reflect the decision maker's preferences regarding the relative importance of each goal; for example: in order to minimize total costs (goal C), its penalty weight should be multiplied by the amount over the costs target determined in step 2. Also, in order to minimize total number of top performers fired (goal P), its 
penalty costs should be multiplied by the amount under the desired number that can be achieved, and so on.

- Solve the combined objective function that minimizes the deviational variables which represents all goals.

A normalization scheme technique is presented to scale all unwanted deviations to a $0-1$ range. The value zero represents a deviation of zero and the value one represents the worst (highest) possible value of the deviation within the feasible set. The one value can be found by a single-objective maximization or minimization depending on the objective function. However, it is not possible to find this value when the objective function is unbounded. Table 1 illustrates the worst possible values of unwanted deviational variables.

\begin{tabular}{|c|r|}
\hline Unwanted Deviation & Maximum Value \\
\hline$d^{+}{ }_{C}$ & $455,995.4$ \\
\hline$d^{+}{ }_{P}$ & $1,142.3$ \\
\hline$d^{+}{ }_{B}$ & $4,098.2$ \\
\hline$d^{+}{ }_{F}$ & 27.1 \\
\hline
\end{tabular}

Table 1. the Worst Possible of Deviational Variables

This leads to the following objective function with the same set of constraints given previously.

$$
O B J=w_{1} \times\left(\frac{d_{C}^{+}}{4559954}\right)+w_{2} \times\left(\frac{d_{P}^{+}}{11423}\right)+w_{3} \times\left(\frac{d_{B}^{+}}{40982}\right)+w_{4} \times\left(\frac{d_{F}^{+}}{27.1}\right)
$$

The next section presents the resulting solution for the given problem.

\section{Computational results}

In this section, the feasibility of applying the proposed method is demonstrated to assess the effect of workers' differences on the workforce schedule. Insights on the effect of various human factors on workforce scheduling decisions are presented. The sensitivity of decision parameters to the variations of relevant conditions based on the numerical example is tested to show the effects of fatigue level and personality levels on workforce decisions and performance.

\subsection{Numerical example}

Model validation ensures that the model addresses the right problem, provides accurate information about the real system being modelled, and makes the model actually usable. In this section, a numerical example is given in order to demonstrate the application of the model; we assume a company produces its products to fulfil known demand along an 8-period planning horizon. Also, it is assumed that the worker is available for 8 hours a day (160 hours 
per month) at regular time and for 2 hours a day ( 80 hours per month) at overtime. However, it is assumed that a worker is not productive during daily breaks and interruptions. Also, the maximum fatigue load a worker can accumulate in any task depends on the personality level. Many jobs require human effort, and some recovery allowance must be made from fatigue for relaxation. We assume that a worker with a high personality level and in top physical condition requires a smaller allowance to recover from fatigue than a low personality level worker. However, other factors such as the factors related to the nature of the work itself and the environment might affect the amount of relaxation allowances needed. Moreover, input data is shown in Tables 2 to 7. The known demand of worker skills in worker-hours in each period is summarized in Table 2. Table 3 shows workers' availabilities. Table 4 shows the available workforce at period zero. Next, Table 5 shows the cost of training from skill level to another skill level in each period. Workers daily salary, hiring costs, lay-off costs, overtime costs and workers' capacities are shown in Table 6. Finally, Table 7 shows the values of the maximum endurance time, fatigue fractions and the recovery rates for different workers. These values are estimated based on the formulas, which are adapted from Jaber and Neumann (2010). Using the input data presented, the model consists of 7,364 variables and 12,929 constraints and the optimal solution for the problem can be easily obtained using LINGO 13.0 software in less than a minute of program running.

\begin{tabular}{|l|c|c|c|c|c|c|c|c|}
\cline { 2 - 9 } \multicolumn{1}{c|}{} & D1 $^{\text {a }}$ & D2 & D3 & D4 & D5 & D6 & D7 & D8 \\
\hline Worker Skill 1 & 320.0 & 160.0 & 320.0 & 320.0 & 320.0 & 320.0 & 320.0 & 320.0 \\
\hline Worker Skill 2 & 400.0 & 320.0 & 320.0 & 320.0 & 400.0 & 160.0 & 320.0 & 480.0 \\
\hline Worker Skill 3 & 400.0 & 480.0 & 480.0 & 480.0 & 320.0 & 160.0 & 320.0 & 320.0 \\
\hline
\end{tabular}

${ }^{a}$ D1 represents Day 1

Table 2. Demand of Worker Skills in Each Week (worker-hours)

\begin{tabular}{|l|l|l|l|l|l|l|l|l|l|}
\cline { 3 - 8 } \multicolumn{2}{c|}{} & D1 & D2 & D3 & D4 & D5 & D6 & D7 & D8 \\
\hline \multirow{3}{*}{ Worker Skill 1} & Availability (regular time) & 8.0 & 8.0 & 8.0 & 8.0 & 8.0 & 8.0 & 8.0 & 8.0 \\
\cline { 2 - 9 } & Availability (overtime) & 2.0 & 2.0 & 2.0 & 2.0 & 2.0 & 2.0 & 2.0 & 2.0 \\
\hline \multirow{3}{*}{ Worker Skill 2} & Availability (regular time) & 8.0 & 8.0 & 8.0 & 8.0 & 8.0 & 8.0 & 8.0 & 8.0 \\
\cline { 2 - 10 } & Availability (overtime) & 2.0 & 2.0 & 2.0 & 2.0 & 2.0 & 2.0 & 2.0 & 2.0 \\
\hline \multirow{2}{*}{ Worker Skill 3 3} & Availability (regular time) & 8.0 & 8.0 & 8.0 & 8.0 & 8.0 & 8.0 & 8.0 & 8.0 \\
\cline { 2 - 10 } & Availability (overtime) & 2.0 & 2.0 & 2.0 & 2.0 & 2.0 & 2.0 & 2.0 & 2.0 \\
\hline
\end{tabular}

Table 3. Workers' Availabilities (worker-hours) 


\begin{tabular}{|c|c|c|c|c|}
\hline & & Machine Level 1 & Machine Level 2 & Machine Level 3 \\
\hline \multirow{3}{*}{ Worker Skill 1} & $\mathbf{P 1}^{\mathbf{b}}$ & 20.0 & 0.0 & 0.0 \\
\hline & P2 & 10.0 & 0.0 & 0.0 \\
\hline & P3 & 5.0 & 0.0 & 0.0 \\
\hline \multirow{3}{*}{ Worker Skill 2} & P1 & 5.0 & 10.0 & 0.0 \\
\hline & P2 & 10.0 & 5.0 & 0.0 \\
\hline & P3 & 5.0 & 10.0 & 0.0 \\
\hline \multirow{3}{*}{ Worker Skill 3} & P1 & 5.0 & 0.0 & 10.0 \\
\hline & P2 & 0.0 & 10.0 & 0.0 \\
\hline & P3 & 10.0 & 5.0 & 10.0 \\
\hline
\end{tabular}

Table 4. Initial Workforce Available in Each Machine Level (workers)

\begin{tabular}{|l|l|l|l|l|l|l|l|l|l|l|}
\hline \multirow{2}{*}{ From } & & To & D1 & D2 & D3 & D4 & D5 & D6 & D7 & D8 \\
\hline \multirow{3}{*}{ Worker Skill 1 } & P1 & Skill 2 & 4.0 & 4.0 & 4.0 & 4.0 & 4.0 & 4.0 & 4.0 & 4.0 \\
\cline { 2 - 11 } & P2 & Skill 2 & 5.0 & 5.0 & 5.0 & 5.0 & 5.0 & 5.0 & 5.0 & 5.0 \\
\cline { 2 - 11 } & P3 & Skill 2 & 6.0 & 6.0 & 6.0 & 6.0 & 6.0 & 6.0 & 6.0 & 6.0 \\
\hline \multirow{3}{*}{ Worker Skill 2 } & P1 & Skill 3 & 4.0 & 4.0 & 4.0 & 4.0 & 4.0 & 4.0 & 4.0 & 4.0 \\
\cline { 2 - 10 } & P2 & Skill 3 & 5.0 & 5.0 & 5.0 & 5.0 & 5.0 & 5.0 & 5.0 & 5.0 \\
\cline { 2 - 10 } & P3 & Skill 3 & 6.0 & 6.0 & 6.0 & 6.0 & 6.0 & 6.0 & 6.0 & 6.0 \\
\hline
\end{tabular}

Table 5. Training Costs in Each Period (\$/worker-days)

Results from the model are shown in Table 8 and 9. In this paper, many human factors such as workers' training, skills, overtime, workers' availabilities, workers' breaks, workers' personalities and workers' fatigue are considered to show their importance at the early planning stages. However, the results from the model offer staffing decisions on what, how and when to hire, fire and train. Also, the number of worker-hours during regular time and overtime and the number of hours during breaks workers can take are determined. The optimal plan is obtained based on the present input data; if the prioritization of the goals and initial settings is modified, the results are likely to be different.

\begin{tabular}{|c|c|c|c|c|c|c|c|c|c|c|}
\hline & \\
\hline & & & D1 & D2 & D3 & D4 & D5 & D6 & D7 & D8 \\
\hline \multirow{12}{*}{ Worker Skill 1} & \multirow{4}{*}{ P1 } & Salary & 100.0 & 100.0 & 100.0 & 100.0 & 100.0 & 100.0 & 100.0 & 100.0 \\
\hline & & Hiring Costs & 80.0 & 80.0 & 80.0 & 80.0 & 80.0 & 80.0 & 80.0 & 80.0 \\
\hline & & Firing Costs & 95.0 & 95.0 & 95.0 & 95.0 & 95.0 & 95.0 & 95.0 & 95.0 \\
\hline & & Overtime & 18.5 & 18.5 & 18.5 & 18.5 & 18.5 & 18.5 & 18.5 & 18.5 \\
\hline & \multirow{4}{*}{ P2 } & Salary & 110.0 & 110.0 & 110.0 & 110.0 & 110.0 & 110.0 & 110.0 & 110.0 \\
\hline & & Hiring Costs & 85.0 & 85.0 & 85.0 & 85.0 & 85.0 & 85.0 & 85.0 & 85.0 \\
\hline & & Firing Costs & 100.0 & 100.0 & 100.0 & 100.0 & 100.0 & 100.0 & 100.0 & 100.0 \\
\hline & & Overtime & 20.5 & 20.5 & 20.5 & 20.5 & 20.5 & 20.5 & 20.5 & 20.5 \\
\hline & \multirow{4}{*}{ P3 } & Salary & 120.0 & 120.0 & 120.0 & 120.0 & 120.0 & 120.0 & 120.0 & 120.0 \\
\hline & & Hiring Costs & 90.0 & 90.0 & 90.0 & 90.0 & 90.0 & 90.0 & 90.0 & 90.0 \\
\hline & & Firing Costs & 115.0 & 115.0 & 115.0 & 115.0 & 115.0 & 115.0 & 115.0 & 115.0 \\
\hline & & Overtime & 22.5 & 22.5 & 22.5 & 22.5 & 22.5 & 22.5 & 22.5 & 22.5 \\
\hline
\end{tabular}




\begin{tabular}{|c|c|c|c|c|c|c|c|c|c|c|}
\hline & \\
\hline & & & D1 & D2 & D3 & D4 & D5 & D6 & D7 & D8 \\
\hline \multirow{12}{*}{ Worker Skill 2} & \multirow{4}{*}{ P1 } & Salary & 130.0 & 130.0 & 130.0 & 130.0 & 130.0 & 130.0 & 130.0 & 130.0 \\
\hline & & Hiring Costs & 95.0 & 95.0 & 95.0 & 95.0 & 95.0 & 95.0 & 95.0 & 95.0 \\
\hline & & Firing Costs & 120.0 & 120.0 & 120.0 & 120.0 & 120.0 & 120.0 & 120.0 & 120.0 \\
\hline & & Overtime & 24.5 & 24.5 & 24.5 & 24.5 & 24.5 & 24.5 & 24.5 & 24.5 \\
\hline & \multirow{4}{*}{ P2 } & Salary & 140.0 & 140.0 & 140.0 & 140.0 & 140.0 & 140.0 & 140.0 & 140.0 \\
\hline & & Hiring Costs & 100.0 & 100.0 & 100.0 & 100.0 & 100.0 & 100.0 & 100.0 & 100.0 \\
\hline & & Firing Costs & 125.0 & 125.0 & 125.0 & 125.0 & 125.0 & 125.0 & 125.0 & 125.0 \\
\hline & & Overtime & 26.5 & 26.5 & 26.5 & 26.5 & 26.5 & 26.5 & 26.5 & 26.5 \\
\hline & \multirow{4}{*}{ P3 } & Salary & 150.0 & 150.0 & 150.0 & 150.0 & 150.0 & 150.0 & 150.0 & 150.0 \\
\hline & & Hiring Costs & 115.0 & 115.0 & 115.0 & 115.0 & 115.0 & 115.0 & 115.0 & 115.0 \\
\hline & & Firing Costs & 140.0 & 140.0 & 140.0 & 140.0 & 140.0 & 140.0 & 140.0 & 140.0 \\
\hline & & Overtime & 28.5 & 28.5 & 28.5 & 28.5 & 28.5 & 28.5 & 28.5 & 28.5 \\
\hline \multirow{12}{*}{ Worker Skill 3} & \multirow{4}{*}{$\mathrm{P} 1$} & Salary & 160.0 & 160.0 & 160.0 & 160.0 & 160.0 & 160.0 & 160.0 & 160.0 \\
\hline & & Hiring Costs & 120.0 & 120.0 & 120.0 & 120.0 & 120.0 & 120.0 & 120.0 & 120.0 \\
\hline & & Firing Costs & 145.0 & 145.0 & 145.0 & 145.0 & 145.0 & 145.0 & 145.0 & 145.0 \\
\hline & & Overtime & 30.0 & 30.0 & 30.0 & 30.0 & 30.0 & 30.0 & 30.0 & 30.0 \\
\hline & \multirow{4}{*}{$\mathrm{P} 2$} & Salary & 170.0 & 170.0 & 170.0 & 170.0 & 170.0 & 170.0 & 170.0 & 170.0 \\
\hline & & Hiring Costs & 125.0 & 125.0 & 125.0 & 125.0 & 125.0 & 125.0 & 125.0 & 125.0 \\
\hline & & Firing Costs & 140.0 & 140.0 & 140.0 & 140.0 & 140.0 & 140.0 & 140.0 & 140.0 \\
\hline & & Overtime & 32.5 & 32.5 & 32.5 & 32.5 & 32.5 & 32.5 & 32.5 & 32.5 \\
\hline & \multirow{4}{*}{ P3 } & Salary & 180.0 & 180.0 & 180.0 & 180.0 & 180.0 & 180.0 & 180.0 & 180.0 \\
\hline & & Hiring Costs & 140.0 & 140.0 & 140.0 & 140.0 & 140.0 & 140.0 & 140.0 & 140.0 \\
\hline & & Firing Costs & 145.0 & 145.0 & 145.0 & 145.0 & 145.0 & 145.0 & 145.0 & 145.0 \\
\hline & & Overtime & 33.5 & 33.5 & 33.5 & 33.5 & 33.5 & 33.5 & 33.5 & 33.5 \\
\hline
\end{tabular}

Table 6. Salary, Hiring, Firing, and Hourly Overtime Costs (\$)

\begin{tabular}{|c|c|c|c|c|c|c|c|c|c|c|c|}
\hline & & $F_{\max }$ & $\mathrm{T} 1^{\mathrm{c}}$ & $\mathrm{T} 2$ & T3 & $\mathrm{T} 4$ & T5 & T6 & T7 & T8 & T9 \\
\hline \multirow{3}{*}{ Fatigue fraction } & P1 & 0.88 & 0.80 & 0.80 & 0.80 & - & - & - & - & - & - \\
\hline & P2 & 0.60 & 0.50 & 0.50 & 0.50 & 0.50 & 0.50 & 0.50 & - & - & - \\
\hline & P3 & 0.13 & 0.10 & 0.10 & 0.10 & 0.10 & 0.10 & 0.10 & 0.10 & 0.10 & 0.10 \\
\hline \multirow{3}{*}{ Recovery rate } & P1 & 0.88 & 0.52 & 0.52 & 0.52 & - & - & - & - & - & - \\
\hline & $\mathrm{P} 2$ & 0.60 & 0.51 & 0.51 & 0.51 & 0.51 & 0.51 & 0.51 & - & - & - \\
\hline & P3 & 0.13 & 0.49 & 0.49 & 0.49 & 0.49 & 0.49 & 0.49 & 0.49 & 0.49 & 0.49 \\
\hline \multirow{3}{*}{ Endurance time } & P1 & 0.88 & 1.10 & 1.10 & 1.10 & - & - & - & - & - & - \\
\hline & $\mathrm{P} 2$ & 0.60 & 1.17 & 1.17 & 1.17 & 1.17 & 1.17 & 1.17 & - & - & - \\
\hline & P3 & 0.13 & 1.27 & 1.27 & 1.27 & 1.27 & 1.27 & 1.27 & 1.27 & 1.27 & 1.27 \\
\hline
\end{tabular}

${ }^{\mathrm{C}} \mathrm{T} 1$ represents Task 1

Table 7. Fatigue Levels and Recovery Rates 


\begin{tabular}{|c|c|c|c|c|c|c|c|c|c|c|}
\hline & & & D1 & D2 & D3 & D4 & D5 & D6 & D7 & D8 \\
\hline & & Demand (workers) & 40.0 & 20.0 & 40.0 & 40.0 & 40.0 & 40.0 & 40.0 & 40.0 \\
\hline \multirow{12}{*}{ Worker Skill 1} & \multirow{4}{*}{ P1 } & Workers used on level 1 & 29.1 & 22.1 & 44.2 & 44.2 & 44.2 & 44.2 & 44.2 & 44.2 \\
\hline & & Workers hired on level 1 & 23.9 & 0.0 & 22.1 & 0.0 & 11.1 & 0.0 & 27.7 & 22.1 \\
\hline & & Workers fired from level 1 & 0.0 & 7.0 & 0.0 & 0.0 & 0.0 & 0.0 & 0.0 & 0.0 \\
\hline & & Workers trained to Level 2 & 14.8 & 0.0 & 0.0 & 0.0 & 11.1 & 0.0 & 27.7 & 22.1 \\
\hline & \multirow{4}{*}{ P2 } & Workers used on level 1 & 10.0 & 0.0 & 0.0 & 0.0 & 0.0 & 0.0 & 0.0 & 0.0 \\
\hline & & Workers hired on level 1 & 0.0 & 0.0 & 0.0 & 0.0 & 0.0 & 0.0 & 0.0 & 0.0 \\
\hline & & Workers fired from level 1 & 0.0 & 10.0 & 0.0 & 0.0 & 0.0 & 0.0 & 0.0 & 0.0 \\
\hline & & Workers trained to Level 2 & 0.0 & 0.0 & 0.0 & 0.0 & 0.0 & 0.0 & 0.0 & 0.0 \\
\hline & \multirow{4}{*}{ P3 } & Workers used on level 1 & 5.0 & 0.0 & 0.0 & 0.0 & 0.0 & 0.0 & 0.0 & 0.0 \\
\hline & & Workers hired on level 1 & 0.0 & 0.0 & 0.0 & 0.0 & 0.0 & 0.0 & 0.0 & 0.0 \\
\hline & & Workers fired from level 1 & 0.0 & 5.0 & 0.0 & 0.0 & 0.0 & 0.0 & 0.0 & 0.0 \\
\hline & & Workers trained to Level 2 & 0.0 & 0.0 & 0.0 & 0.0 & 0.0 & 0.0 & 0.0 & 0.0 \\
\hline & & Demand (workers) & 50.0 & 40.0 & 40.0 & 40.0 & 50.0 & 20.0 & 40.0 & 60.0 \\
\hline \multirow{15}{*}{ Worker Skill 2} & \multirow{5}{*}{ P1 } & Workers used on level 1 & 5.0 & 5.0 & 5.0 & 5.0 & 5.0 & 0.0 & 0.0 & 0.0 \\
\hline & & Workers used on level 2 & 19.9 & 8.9 & 8.9 & 8.9 & 19.9 & 0.0 & 27.7 & 49.8 \\
\hline & & Workers hired on level $1 \& 2$ & 0.0 & 0.0 & 0.0 & 0.0 & 0.0 & 0.0 & 0.0 & 0.0 \\
\hline & & Workers fired from level $1 \& 2$ & 0.0 & 0.0 & 0.0 & 0.0 & 0.0 & 0.0 & 25.0 & 0.0 \\
\hline & & Workers trained to Level 3 & 4.8 & 11.1 & 0.0 & 0.0 & 0.0 & 0.0 & 0.0 & 0.0 \\
\hline & \multirow{5}{*}{ P2 } & Workers used on level 1 & 10.0 & 10.0 & 10.0 & 10.0 & 10.0 & 10.0 & 10.0 & 10.0 \\
\hline & & Workers used on level 2 & 5.0 & 5.0 & 5.0 & 5.0 & 5.0 & 5.0 & 1.4 & 1.4 \\
\hline & & Workers hired on level $1 \& 2$ & 0.0 & 0.0 & 0.0 & 0.0 & 0.0 & 0.0 & 0.0 & 0.0 \\
\hline & & Workers fired from level $1 \& 2$ & 0.0 & 0.0 & 0.0 & 0.0 & 0.0 & 0.0 & 0.0 & 0.0 \\
\hline & & Workers trained to Level 3 & 0.0 & 0.0 & 0.0 & 0.0 & 0.0 & 0.0 & 3.6 & 0.0 \\
\hline & \multirow{5}{*}{ P3 } & Workers used on level 1 & 5.0 & 5.0 & 5.0 & 5.0 & 5.0 & 5.0 & 5.0 & 5.0 \\
\hline & & Workers used on level 2 & 10.0 & 10.0 & 10.0 & 10.0 & 10.0 & 10.0 & 0.0 & 0.0 \\
\hline & & Workers hired on level $1 \& 2$ & 0.0 & 0.0 & 0.0 & 0.0 & 0.0 & 0.0 & 0.0 & 0.0 \\
\hline & & Workers fired from level $1 \& 2$ & 0.0 & 0.0 & 0.0 & 0.0 & 0.0 & 0.0 & 0.0 & 0.0 \\
\hline & & Workers trained to Level 3 & 0.5 & 0.0 & 0.0 & 0.0 & 0.0 & 0.0 & 10.0 & 0.0 \\
\hline & & Demand (workers) & $\mathbf{5 0 . 0}$ & 60.0 & 60.0 & 60.0 & 40.0 & 20.0 & 40.0 & 40.0 \\
\hline \multirow{15}{*}{ Worker Skill 3} & \multirow{5}{*}{ P1 } & Workers used on level 1 & 5.0 & 5.0 & 5.0 & 5.0 & 5.0 & 0.0 & 0.0 & 0.0 \\
\hline & & Workers used on level 2 & 0.0 & 0.0 & 0.0 & 0.0 & 0.0 & 0.0 & 0.0 & 0.0 \\
\hline & & Workers used on level 3 & 14.8 & 25.9 & 25.9 & 25.9 & 8.8 & 0.0 & 0.0 & 0.0 \\
\hline & & Workers hired on level $1,2 \& 3$ & 0.0 & 0.0 & 0.0 & 0.0 & 0.0 & 0.0 & 0.0 & 0.0 \\
\hline & & Workers fired from level $1 \& 2 \& 3$ & 0.0 & 0.0 & 0.0 & 0.0 & 17.1 & 13.8 & 0.0 & 0.0 \\
\hline & \multirow{5}{*}{ P2 } & Workers used on level 1 & 0.0 & 0.0 & 0.0 & 0.0 & 0.0 & 0.0 & 0.0 & 0.0 \\
\hline & & Workers used on level 2 & 10.0 & 10.0 & 10.0 & 10.0 & 5.0 & 5.0 & 5.0 & 5.0 \\
\hline & & Workers used on level 3 & 0.0 & 0.0 & 0.0 & 0.0 & 0.0 & 0 & 3.6 & 3.6 \\
\hline & & Workers hired on level $1,2 \& 3$ & 0.0 & 0.0 & 0.0 & 0.0 & 0.0 & 0.0 & 0.0 & 0.0 \\
\hline & & Workers fired from level $1 \& 2 \& 3$ & 0.0 & 0.0 & 0.0 & 0.0 & 5.0 & 0.0 & 0.0 & 0.0 \\
\hline & \multirow{5}{*}{ P3 } & Workers used on level 1 & 10.0 & 10.0 & 10.0 & 10.0 & 10.0 & 10.0 & 10.0 & 10.0 \\
\hline & & Workers used on level 2 & 5.0 & 5.0 & 5.0 & 5.0 & 5.0 & 5.0 & 5.0 & 5.0 \\
\hline & & Workers used on level 3 & 10.0 & 10.0 & 10.0 & 10.0 & 10.0 & 10.0 & 20.0 & 20.0 \\
\hline & & Workers hired on level $1,2 \& 3$ & 0.0 & 0.0 & 0.0 & 0.0 & 0.0 & 0.0 & 0.0 & 0.0 \\
\hline & & Workers fired from level $1 \& 2 \& 3$ & 0.0 & 0.0 & 0.0 & 0.0 & 0.0 & 0.0 & 0.0 & 0.0 \\
\hline
\end{tabular}

Table 8. Resulting Workforce Plan in Number of Workers 


\begin{tabular}{|c|c|c|c|c|c|c|c|c|c|c|}
\hline & & & D1 & D2 & D3 & D4 & D5 & D6 & D7 & D8 \\
\hline & & Demand (hours) & 320.0 & 160.0 & 320.0 & 320.0 & 320.0 & 320.0 & 320.0 & 320.0 \\
\hline \multirow{9}{*}{ Worker Skill 1} & \multirow{3}{*}{ P1 } & Regular time on level 1 & 152.3 & 115.8 & 231.6 & 231.5 & 231.5 & 231.5 & 231.5 & 231.5 \\
\hline & & Breaks 1 & 80.3 & 61.0 & 122.0 & 122.0 & 122.0 & 122.0 & 122.0 & 120.0 \\
\hline & & Overtime Hours & 58.1 & 44.2 & 88.4 & 88.4 & 88.4 & 88.4 & 88.4 & 88.4 \\
\hline & \multirow{3}{*}{ P2 } & Regular time on level 1 & 52.8 & 0.0 & 0.0 & 0.0 & 0.0 & 0.0 & 0.0 & 0.0 \\
\hline & & Breaks 1 & 27.0 & 0.0 & 0.0 & 0.0 & 0.0 & 0.0 & 0.0 & 0.0 \\
\hline & & Overtime Hours & 20.0 & 0.0 & 0.0 & 0.0 & 0.0 & 0.0 & 0.0 & 0.0 \\
\hline & \multirow{3}{*}{ P3 } & Regular time on level 1 & 26.7 & 0.0 & 0.0 & 0.0 & 0.0 & 0.0 & 0.0 & 0.0 \\
\hline & & Breaks 1 & 13.3 & 0.0 & 0.0 & 0.0 & 0.0 & 0.0 & 0.0 & 0.0 \\
\hline & & Overtime Hours & 10.0 & 0.0 & 0.0 & 0.0 & 0.0 & 0.0 & 0.0 & 0.0 \\
\hline & & Demand (hours) & 400.0 & 320.0 & 320.0 & 320.0 & 400.0 & 160.0 & 320.0 & 480.0 \\
\hline \multirow{12}{*}{ Worker Skill 2} & \multirow{4}{*}{ P1 } & Regular time on level 1 & 26.2 & 26.2 & 26.2 & 26.2 & 26.2 & 0.0 & 0.0 & 0.0 \\
\hline & & Regular time on level 2 & 104.5 & 46.6 & 46.6 & 46.6 & 104.5 & 0.0 & 145.2 & 261.0 \\
\hline & & Breaks $1 \& 2$ & 68.9 & 38.4 & 38.4 & 38.4 & 68.9 & 0.0 & 76.5 & 137.5 \\
\hline & & Overtime Hours & 49.8 & 27.8 & 27.8 & 27.8 & 49.8 & 0.0 & 55.4 & 99.6 \\
\hline & \multirow{4}{*}{ P2 } & Regular time on level 1 & 52.8 & 52.8 & 52.8 & 52.8 & 52.8 & 52.8 & 52.8 & 52.8 \\
\hline & & Regular time on level 2 & 26.4 & 26.4 & 26.4 & 26.4 & 26.4 & 26.4 & 7.1 & 7.1 \\
\hline & & Breaks $1 \& 2$ & 40.7 & 40.7 & 40.7 & 40.7 & 40.7 & 40.7 & 30.8 & 30.8 \\
\hline & & Overtime Hours & 30.0 & 30.0 & 30.0 & 30.0 & 30.0 & 0.6 & 22.7 & 22.7 \\
\hline & \multirow{4}{*}{ P3 } & Regular time on level 1 & 26.7 & 26.7 & 26.7 & 26.7 & 26.7 & 26.7 & 26.7 & 26.7 \\
\hline & & Regular time on level 2 & 53.4 & 53.4 & 53.4 & 53.4 & 53.4 & 53.4 & 0.0 & 0.0 \\
\hline & & Breaks $1 \& 2$ & 39.8 & 39.8 & 39.8 & 39.8 & 39.8 & 39.8 & 13.3 & 13.3 \\
\hline & & Overtime Hours & 30.0 & 30.0 & 30.0 & 30.0 & 30.0 & 0.0 & 10.0 & 10.0 \\
\hline & & Demand (hours) & 400.0 & 480.0 & 480.0 & 480.0 & 320.0 & 160.0 & 320.0 & 320.0 \\
\hline \multirow{15}{*}{ Worker Skill 3} & \multirow{5}{*}{ P1 } & Regular time on level 1 & 26.2 & 26.2 & 26.2 & 26.2 & 0.0 & 0.0 & 0.0 & 26.2 \\
\hline & & Regular time on level 2 & 0.0 & 0.0 & 0.0 & 0.0 & 0.0 & 0.0 & 0.0 & 0.0 \\
\hline & & Regular time on level 3 & 77.7 & 135.6 & 135.6 & 135.6 & 46.2 & 0.0 & 0.0 & 0.0 \\
\hline & & Breaks $1 \& 2 \& 3$ & 54.8 & 85.3 & 85.3 & 85.3 & 38.1 & 0.0 & 0.0 & 0.0 \\
\hline & & Overtime Hours & 39.6 & 61.7 & 61.7 & 61.7 & 27.6 & 0.0 & 0.0 & 0.0 \\
\hline & \multirow{5}{*}{$\mathrm{P} 2$} & Regular time on level 1 & 0.0 & 0.0 & 0.0 & 0.0 & 0.0 & 0.0 & 0.0 & 0.0 \\
\hline & & Regular time on level 2 & 52.8 & 52.8 & 52.8 & 52.8 & 26.4 & 26.4 & 26.4 & 26.4 \\
\hline & & Regular time on level 3 & 0.0 & 0.0 & 0.0 & 0.0 & 0.0 & 0.0 & 19.3 & 19.3 \\
\hline & & Breaks $1 \& 2 \& 3$ & 27.2 & 27.2 & 27.2 & 27.2 & 13.6 & 13.6 & 23.5 & 23.5 \\
\hline & & Overtime Hours & 20.0 & 20.0 & 20.0 & 20.0 & 10.0 & 0.0 & 17.3 & 17.3 \\
\hline & \multirow{5}{*}{ P3 } & Regular time on level 1 & 53.4 & 53.4 & 53.4 & 53.4 & 53.4 & 53.4 & 53.4 & 53.4 \\
\hline & & Regular time on level 2 & 26.7 & 26.7 & 26.7 & 26.7 & 26.7 & 26.7 & 26.7 & 26.7 \\
\hline & & Regular time on level 3 & 53.4 & 53.4 & 53.4 & 53.4 & 53.4 & 53.4 & 106.9 & 106.9 \\
\hline & & Breaks $1 \& 2 \& 3$ & 66.4 & 66.4 & 66.4 & 66.4 & 66.4 & 66.4 & 128.9 & 86.9 \\
\hline & & Overtime Hours & 50.0 & 50.0 & 50.0 & 50.0 & 50.0 & 0.0 & 70.0 & 70.0 \\
\hline
\end{tabular}

Table 9. Resulting Workforce Plan in Worker-hours

This research shows that workers' differences can be used to predict hiring, firing and training workers and total break time. Table 8 shows the number of workers hired, fired and trained in each period for different personality levels. Also, Table 9 shows the time workers spend on all the tasks to satisfy the demand and the amount of break they take due to the fatigue level for each worker. From Tables 8 and 9, it can be seen that the workers who are not working during regular time have no breaks. Also, we can notice from running the model with different objectives that a worker at higher personality level required less amount of break to recover than a worker with low personality level. Moreover, the most of the workers hired and trained have low personality level, which represents the normal scenario in practice since it is assumed 
the lower personality levels workers costs less than workers with high personality levels. However, these results will be different if the input data are changed or when the company goals are changed, as shown in Table 10. For example, if we considered different productivities for different workers personality levels, the model will prefer to hire and use workers with higher personality levels because of their high performance.

\subsection{Model implementation and results analysis}

All workers have the right to take breaks. The actual amount of break a worker receives is usually set out in his contract of employment. Although there are some kinds of jobs that do not allow workers to take breaks such as air or sea transport and working part time during busy peak periods, not taking a break can result in overloaded, stressed, and unproductive workers. Rest breaks are one of break types that workers can take under special rules written in the employment contact. This model can help to estimate the amount of break a worker can take during a working day in order to minimize the risk caused by worker fatigue. In the previous section, a simple numerical example is given to illustrate the performance of the model. In this section, we will study the effects of fatigue level and worker differences on workforce decisions. Table 10 shows a comparison between the two cases with different goals. Also, it shows a comparison between two cases; the first one represents the case where fatigue level is different and the second one represents the case where the fatigue level is the same. However, considering human differences that exist between workers results in more accurate workforce decisions. In Table 10, it is assumed that the fractions of maximum workers' capability are set to be the average values. This fraction can be used to determine the values of maximum endurance time, recovery rate and maximum fatigue. Also, it is assumed that we decision maker is looking to achieve three goals; costs minimization, the number of top performers fired minimization and idle time minimization.

\begin{tabular}{|c|c|c|c|c|c|c|}
\hline Total & Goal 1 & Goal 2 & Goal 3 & Goal 4 & $\begin{array}{c}\text { Equal weights } \\
\text { (Different fatigue) }\end{array}$ & $\begin{array}{c}\text { Equal weights } \\
\text { (Same fatigue) }\end{array}$ \\
\hline Objective Value & $223,618.2$ & 1.9 & 2846.6 & 0.0 & 0.05 & 0.03 \\
\hline Demand (W'.days) & $8,080.0$ & $8,080.0$ & $8,080.0$ & $8,080.0$ & $8,080.0$ & $8,080.0$ \\
\hline Regular Time (hrs) & $6,270.8$ & $7,883.5$ & $5,894.5$ & 8,080 & $5,967.5$ & $5,962.3$ \\
\hline Overtime (hrs) & $1,810.223$ & 206.0 & $2,185.3$ & 0.0 & $2,112.5$ & $2,117.6$ \\
\hline Breaks (W.hrs) & $3,295.5$ & $3,957.5$ & $2,846.5$ & 4,021 & $2,955.2$ & $2,984.1$ \\
\hline Workers (W.days) & $1,195.7$ & $1,478.9$ & 1092.7 & $1,512.6$ & $1,115.3$ & $1,118.3$ \\
\hline Training (W.days) & 77.2 & 21.8 & 82.9 & 54.9 & 101.4 & 115.9 \\
\hline Hiring (W.days) & 70.4 & 265.5 & 249.5 & 344.8 & 104.9 & 105.8 \\
\hline Firing (W.days) & 46.9 & 186.6 & 227.9 & 264.7 & 82.5 & 82.6 \\
\hline Fatigue (\%.hr) & 68.4 & 45.3 & 76.3 & 0.0 & 72.9 & 83.9 \\
\hline Costs (\$) & $223,618.2$ & $273,341.2$ & $286,859.8$ & $304,191.0$ & $229,798.0$ & $230,056.5$ \\
\hline
\end{tabular}

${ }^{\mathrm{d}} \mathrm{W}$ represents Worker

Table 10. Comparisons Between the Different Goals 
This table shows the comparisons between the two cases regarding the importance of considering fatigue level differences between workers to generate a better solution. The total cost when fatigue level is same for all workers is $\$ 230,056.5$, but when we consider different fatigue level between workers, the total cost is $\$ 229,798.0$. The results show that by considering worker differences in the model the costs differences are not significant. Also, the present study found that fatigue is not significantly important for scheduling day workers from the economics perspective, but it help to determine the amount of the break workers can take depending on his personality, and salaries profiles. Further research should be done on the effects of the fatigue on worker scheduling with different shifts. Moreover, if the initial number of workers is changed, the number of hired, fired or trained workers is changed which will change the total costs. Also, in Table 9, we can notice that the company can use this model in planning process by selecting the specific goals based on its policy and budget. For example, we can assign a target value for each goal so that we can determine the number of workers needed in each period to satisfy the demand without exceeding the predefined goals.

\subsection{Sensitivity Analysis}

Realistic mixed integer programming models require large amounts of data. Accurate data are expensive to collect, so we will generally be forced to use data in which we have less than complete confidence. This section discusses the actual implementation of the proposed model by manipulating different alternatives and analyzing the sensitivity of decision parameters to the variation of relevant conditions, based on the preceding numerical example.

\subsubsection{Implications Regarding Different Model Goals}

A user of a model should be concerned with how the recommendations of the model are altered by changes in the input data. Table 11 illustrates the comparisons between different scenario problems and the effects of changing the weights of the company goals on the total costs and utilization of the work. In this Table, we implement 10 scenarios to compare between the final results in terms of workers' utilization, workers' fatigue, and the total costs. The worker utilization is calculated by dividing the total productive time for all the workers by the total available hours. Worker break percentages represent the amount of break workers can take in average during a working day. Also, workers' fatigue represents the total physical load on the workforce during a working day. We change each scenario by changing the weights of the unwanted deviational variables in the objective function to show its effects on the final objective value. For example, in scenario 1, all goals have the same importance in the objective function.

In the weighted goal programming method, we can use a set of preference weights assigned to the penalisation of unwanted deviations to provide solutions that are of practical use to the problem owner. In this weight space analysis, it is assumed that all weighting vectors have been normalized and hence sum to one. Note that in practice the weight of an unwanted 
deviational variable has to be greater than zero to avoid the possibility of generating Paretoinefficient solutions. Tamiz and Jones (1996) defined Pareto inefficiency as an objective that can be improved without worsening the value of any other objective. Therefore, a small weight (e.g. 0.005) is suggested to replace a zero weight. Heuristic method and sensitivity analysis are developed to find the weight values in the weighting space (Jones \& Tamiz, 2010). By comparing scenario 1 through 10 , we can see that if we add more weight to the cost goal the total costs are reduced. Also, the total fatigue of the workers will be increased if more weight is added to the breaks minimization goal. However, increasing the physical load of the workers may not be desirable due to desired quality levels or occupational health and safety issues. Therefore, the determination of the weight values is a process of interaction with the decision maker(s). By doing this sensitivity analysis we can find the solution that fit with any company requirements. For example, scenarios 3 and 7 give a relatively high value of utilization compared to the other scenarios (e.g. scenario 2). This means that putting more weight on idle time minimization or hiring workers with fast rate recovery can increases workforce utilization. So the company can choose which scenario is best based on its policies and rules. However, sensitivity analysis can reveal which pieces of information should be estimated most carefully.

\begin{tabular}{|c|c|c|c|c|c|c|c|c|}
\hline Goal \# & W1 & W2 & W3 & W4 & Obj. value & Utilization & Fatigue & Costs (\$) \\
\hline 1 & 0.25 & 0.25 & 0.25 & 0.25 & 0.019 & $66.0 \%$ & 0 & $232,122.1$ \\
\hline 2 & 0.991 & 0.003 & 0.003 & 0.003 & 0.002 & $65.4 \%$ & 27.1 & $224,158.5$ \\
\hline 3 & 0.003 & 0.003 & 0.991 & 0.003 & 0.0036 & $67.4 \%$ & 76.3 & $272,090.2$ \\
\hline 4 & 0.003 & 0.003 & 0.003 & 0.991 & 0.0002 & $66.0 \%$ & 0 & $232,122.1$ \\
\hline 5 & 0.495 & 0.005 & 0.495 & 0.005 & 0.027 & $66.3 \%$ & 61.4 & 230.175 .8 \\
\hline 6 & 0.495 & 0.495 & 0.005 & 0.005 & 0.006 & $66.1 \%$ & 5.98 & $228,208.5$ \\
\hline 7 & 0.005 & 0.495 & 0.495 & 0.005 & 0.0017 & $66.9 \%$ & 34.1 & $245,700.4$ \\
\hline 8 & 0.005 & 0.005 & 0.495 & 0.495 & 0.01 & $66.8 \%$ & 0 & $275,017.1$ \\
\hline 9 & 0.495 & 0.005 & 0.005 & 0.495 & 0.0016 & $65.0 \%$ & 0 & $225,177.6$ \\
\hline 10 & 0.005 & 0.495 & 0.005 & 0.495 & 0.0006 & $65.8 \%$ & 0 & $231,985.9$ \\
\hline
\end{tabular}

Table 11. Comparisons between Different Goals

\subsubsection{Impact of Different Loading Levels on the planning Decisions}

One assumption of linear programming is that all the parameters of the model are known constants. Actually, the parameter values used in the model are just estimates based on a prediction of future conditions. Sensitivity analysis investigates the changes to the optimal solution of a model as the result of changes in input data. In this section, some input parameters are studied; recovery allowance, maximum fatigue and maximum endurance time. However, all of these parameters depend on the fractions of the maximum load capabilities of the workers. Table 12 shows the scenarios with different load levels, recovery rates and maximum fatigue levels. So, the three scenarios will be studied based on different load levels. In the first scenario, the lower personality workers recover faster than higher personality level 
workers. Scenario 2 is the same as the previous scenarios except all workers have the same fraction levels equal to 0.5 . Scenario 3 assumes that the load levels are increasing as the personality levels are increasing.

\begin{tabular}{|c|c|c|c|c|c|c|c|c|c|c|c|}
\hline \multicolumn{2}{|c|}{ Scenario } & $F_{\max }$ & $\mathrm{T} 1$ & T2 & T3 & T4 & T5 & T6 & T7 & T8 & T9 \\
\hline \multirow{3}{*}{1} & $\mathrm{P} 1$ & 0.88 & 0.80 & 0.80 & 0.80 & - & - & - & - & - & - \\
\hline & $\mathrm{P} 2$ & 0.58 & 0.50 & 0.50 & 0.50 & 0.50 & 0.50 & 0.50 & - & - & - \\
\hline & P3 & 0.12 & 0.10 & 0.10 & 0.10 & 0.10 & 0.10 & 0.10 & 0.10 & 0.10 & 0.10 \\
\hline \multirow{3}{*}{2} & $\mathrm{P} 1$ & 0.58 & 0.50 & 0.50 & 0.50 & - & - & - & - & - & - \\
\hline & P2 & 0.58 & 0.50 & 0.50 & 0.50 & 0.50 & 0.50 & 0.50 & - & - & - \\
\hline & P3 & 0.58 & 0.50 & 0.50 & 0.50 & 0.50 & 0.50 & 0.50 & 0.50 & 0.50 & 0.50 \\
\hline \multirow{3}{*}{3} & $\mathrm{P} 1$ & 0.12 & 0.10 & 0.10 & 0.10 & - & - & - & - & - & - \\
\hline & P2 & 0.58 & 0.50 & 0.50 & 0.50 & 0.50 & 0.50 & 0.50 & - & - & - \\
\hline & P3 & 0.88 & 0.80 & 0.80 & 0.80 & 0.80 & 0.80 & 0.80 & 0.80 & 0.80 & 0.80 \\
\hline
\end{tabular}

Table 12. Different Scenarios with Different Load Levels $(\alpha=1.3 \beta=0.215)$

Table 13 illustrates these different scenarios showing the costs, utilization and total fatigue for each scenario. In this experiment, we assume that the company is concerned only on the minimization of the total costs incurred. So the effects of other goals are eliminated from the model to compare the results from one perspective.

\begin{tabular}{|c|l|c|c|l|}
\hline Scenario & Fraction & Fatigue & Utilization (\%) & Costs (\$) \\
\hline 1 & Decreasing & 68.4 & 65.6 & $223,618.2$ \\
\hline 2 & Constant & 75.0 & 65.7 & $223,265.7$ \\
\hline 3 & Increasing & 68.6 & 66.1 & $222,295.0$ \\
\hline
\end{tabular}

Table 13. Three Scenarios with Different Loading Levels

The results show the differences in fatigue fractions between the three scenarios do not greatly affect the total costs. However, scenario 3 performs better in terms of costs and fatigue levels. Also, we can see that the workforce decisions are almost the same even though fatigue information is different. The main reason for not having big difference in the results is that the suggested fatigue input parameters are so close and the differences are minimal. However, if we hire fast recovery rates workers without changing other fatigue information, we can see the amount of breaks and costs are reduced significantly.

This experiment clarifies that fatigue is not very important for scheduling day workers from the economics perspective, but it helps to determine the amount of break that workers can take depending on their personal and salaries profiles. 


\section{Conclusions}

In this paper, a new model for integrating workers' differences with workforce scheduling is proposed. It is possible to include some fatigue and recovery aspects into workforce scheduling models to support the production process without overloading the workers. This model can take into account the human aspects such as worker skill, training, breaks, availability, fatigue, and personality to plan the workforce of any company so that customer satisfaction will be achieved with minimum cost. Also, two cases are given to test the influence of worker's differences on the planning process. This research contributes to the production planning problem by incorporating the human aspects as an integral part of the production system.

Specific contributions of this paper include: developing a workforce scheduling model that considers workers' differences, workers' training, workers' skills, workers' availabilities, workers' breaks, workers' fatigue, workers' recovery and workers' personalities. Also, the working levels and possibility of workers training and upgrading are considered. The results show that costs have a significant effect on the selection of workers with different skill ability. Also, workers' fatigue can be incorporated to determine the amount of break that workers can take during their working shift This model helps companies to decide what the best scenario for hiring, firing and training workers can be to satisfy their goals and without changing their rules.

The results of the proposed model depend on the assumptions made for decision parameters such as costs, workers attributes, fatigue and recovery models and the forecasted demand. Hence, it is essential that a company uses assumptions that are in line with the company's policies and practices. Future research could include other human factors such as learning curves and experience in workforce planning problems. Finally, future research might also consider the development of a decision support system that will help managers to solve the model in the context of uncertainty of demand and cost parameters.

In conclusion, this research is believed to be one of the first attempts at incorporating human fatigue and recovery in the planning process. It has been shown that considering technical and human factors together can improve the working conditions and reduce the costs and wastes in manufacturing systems.

\section{References}

Azizi, N., Zolfaghari, S., \& Liang, M. (2010). Modeling job rotation in manufacturing systems: The study of employee's boredom and skill variations. International Journal of Production Economics, 123(1), 69-85. http://dx.doi.org/10.1016/j.ijpe.2009.07.010 
Berglund, M., \& Karltun, J. (2007). Human, technological and organizational aspects influencing the production scheduling process. International Journal of Production Economics, 110(1-2), 160-174. http://dx.doi.org/10.1016/j.ijpe.2007.02.024

Bidanda, B., Ariyawonggrat, P., Needy, K.L., Norman, B.A., \& Tharmmaphornphilas, W. (2005). Human related issues in manufacturing cell design, implementation, and operation: a review and survey. Computers \& Industrial Engineering, 48(3), 507-523. http://dx.doi.org/10.1016/j.cie.2003.03.002

Birch, S., O'Brien-Pallas, L., Alksnis, C., Tomblin Murphy, G., \& Thomson D. (2003). Beyond demographic change in human resources planning: an extended framework and application to nursing. Journal of Health Services Research and Policy, 8(4), 225-229. http://dx.doi.org/10.1258/135581903322403290

Blumberg, M., \& Pringle, C.D. (1982). The missing opportunity in organizational research: some implications for a theory of work performance. Academy of Management Review, 7(4), 560-569.

Butler, M.P. (2003). Corporate ergonomics programme at Scottish \& Newcastle. Applied Ergonomics, 34(1), 35-38. http://dx.doi.org/10.1016/S0003-6870(02)00082-0

Buzacott, J.A. (2002). The impact of worker differences on production system output. International Journal of Production Economics, 78(1), 37-44. http://dx.doi.org/10.1016/S0925-5273(00)00086-4

Castley, R.J. (1996). Policy-focused approach to manpower planning. International Journal of Manpower, 17(3), 15-24. http://dx.doi.org/10.1108/01437729610119487

Cohon, J.L. (1978). Multiobjective programming and planning, New York: Academic Press

Corominas, A, Olivella, J., \& Pastor, R. (2010). A model for assignment of a set of tasks when work performance depends on experience of all tasks involved. International Journal of Production Economics, 126(2), 335-340. http://dx.doi.org/10.1016/j.ijpe.2010.04.012

Da Silva, C.G, Figueira, J., Lisboa, J., \& Barman, S. (2006). An interactive decision support system for an aggregate production planning model based on multiple criteria mixed integer linear programming. The International Journal of Management Science, 34(2), 167-177. http://dx.doi.org/10.1016/j.omega.2004.08.007

De Kluyver, C.A. (1979). An exploration of various goal programming formulations-with application to advertising media scheduling. Journal of the Operational Research Society, $30(2), 167-171$ 
Dul, J., \& Neumann, W.P. (2009). Ergonomics contributions to company strategies. Applied Ergonomics, 40(4), 745-752. http://dx.doi.org/10.1016/j.apergo.2008.07.001

Eklund, J. (1997). Ergonomics, quality and continuous improvement - conceptual and empirical relationships in an industrial context. Ergonomics, 40(10), 982-1001.

Felan, J.T., \& Fry, T.D. (2001). Multi-level heterogeneous worker flexibility in a Dual Resource Constrained (DRC) job-shop. International Journal of Production Research, 39(14), 30413059. http://dx.doi.org/10.1080/00207540110047702

Hägg, G.M., (2003). Corporate initiatives in ergonomics - an introduction. Applied Ergonomics, 34(1), 3-15. http://dx.doi.org/10.1016/S0003-6870(02)00078-9

Helander, M. (1999). Seven common reasons to not implement ergonomics. International Journal of Industrial Ergonomics, 25(1), 97-101. http://dx.doi.org/10.1016/S01698141(98)00097-3

Hillier, F.S., \& Lieberman, G.J. (2010). Introduction to Operations Research, 9th ed., Burr Ridge, IL: Irwin/McGraw-Hill.

Jaber, M.Y., \& Neumann, W.P. (2010). Modeling worker fatigue and recovery in dual-resource constrained systems. Computers \& Industrial Engineering, 59(1), 75-84. http://dx.doi.org/10.1016/j.cie.2010.03.001

Jamalnia, A., \& Soukhakian, M.A. (2009). A hybrid fuzzy goal programming approach with different goal priorities to aggregate production planning. Computers \& Industrial Engineering, 56(4), 1474-1486. http://dx.doi.org/10.1016/j.cie.2008.09.010

Jenkins, S., \& Rickards, J. (2001). The economics of ergonomics: Three workplace design case studies. In: D.C. Alexander \& R. Rabourn (Eds.), Applied ergonomics (pp.238-243), London: Taylor \& Francis.

Jensen P.L. (2002). Human factors and ergonomics in the planning of production. International Journal of Industrial Ergonomics, 29(3), 121-131. http://dx.doi.org/10.1016/S0169$\underline{8141(01) 00056-7}$

Jones, D., \& Tamiz, M. (2010). Practical goal programming. ( $1^{\text {st }}$ ed.). New York, London: Springer

Jones, D.F. (1995). The design and development of an intelligent goal programming system. PhD. Thesis. University of Portsmouth, UK.

Masud, A.S., \& Hwang, C.L. (1981). Interactive sequential goal programming. Journal of the Operational Research Society, 32(5), 391-400. 
Neumann, W.P., \& Medbo, P. (2009). Integrating human factors into discrete event simulations of parallel flow strategies. Production Planning and Control, 20(1), 3-16. http://dx.doi.org/10.1080/09537280802601444

Oxenburgh, M., Marlow, P., \& Oxenburgh, A. (2004). Increasing productivity and profit through health and safety: The financial returns from a safe working environment (2nd Ed.). Boca Raton, Florida: CRC Press.

Perrow, C. (1983). The organizational context of human factor engineering. Administrative Science Quarterly, 28(4), 521-541.

Siebers, P.O. (2004). The impact of human performance variation on the accuracy of manufacturing system simulation models, PhD thesis, Cranfield University, School of Industrial and Manufacturing Science, UK.

Siebers, P.O. (2006). Worker performance modeling in manufacturing systems simulation. In Rennard, J.-P., (Ed.). Handbook of research on nature inspired computing for economy and management (pp. 661-678). Pennsylvania: Idea Group Publishing.

Stewart, B.D., Webster, D.B., Ahmad, S., \& Matson J.O. (1994). Mathematical models for developing a flexible workforce. International Journal of Production Economics, 36(3), 243254. http://dx.doi.org/10.1016/0925-5273(94)00033-6

Tamiz, M., \& Jones, D.F. (1996). Goal programming and Pareto efficiency. Journal of Information and Optimization Sciences, 17(2), 291-3Tamiz, M., Jones, D., \& Romero, C. (1998). Goal programming for decision making: An overview of current state-of-the-art. European Journal of Operational Research, 111(3), 569-581

Torabi S.A., Ebadian M., \& Tanha R. (2010). Fuzzy hierarchical production planning (with a case study). Fuzzy Sets and Systems, 161(11), 1511-1529. http://dx.doi.org/10.1016/j.fss.2009.11.006

Udo, G.G., \& Ebiefung, A.A. (1999). Human factors affecting the success of advanced manufacturing systems. Computers \& Industrial Engineering, 37(1-2), 297-300. http://dx.doi.org/10.1016/S0360-8352(99)00078-9

Widhelm, W.B. (1981). Extensions of goal programming models. The International Journal of Management Science, 9(2), 212-214

Wilson, J.R. (2000). Fundamentals of ergonomics in theory and practice. Applied Ergonomics, 31(6), 557-567. http://dx.doi.org/10.1016/S0003-6870(00)00034-X 
Wirojanagud, P., Gel, E.S., Fowler, J.W., \& Cardy, R. (2007). Modeling inherent worker differences for workforce planning. International Journal of Production Research, 45(3), 525553. http://dx.doi.org/10.1080/00207540600792242

Journal of Industrial Engineering and Management, 2012 (www.jiem.org)

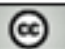

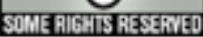

El artículo está con Reconocimiento-NoComercial 3.0 de Creative Commons. Puede copiarlo, distribuirlo y comunicarlo públicamente siempre que cite a su autor y a Intangible Capital. No lo utilice para fines comerciales. La licencia completa se puede consultar en http://creativecommons.org/licenses/by-nc/3.0/es/ 